\title{
Surgical and Orthodontic Treatment of Dental Retentions: A Case Report
}

\author{
Ouédraogo Youssouf ${ }^{1}$, Ouattara Seydou ${ }^{2}$, Sawadogo Augustin ${ }^{3}$, Fall Médina ${ }^{4}$, \\ Kaboré W. Aimé Désiré5, Béogo Rasmané2, Konsem Tarcissus ${ }^{1}$
}

\author{
${ }^{1}$ Département de Chirurgie Dentaire et de Chirurgie Maxillo-Faciale, Centre Hospitalier Universitaire Yalgado Ouédraogo, \\ Ouagadougou, Burkina Faso \\ ${ }^{2}$ Centre Hospitalier Universitaire Sanou Souro, Bobo Dioulasso, Burkina Faso \\ ${ }^{3}$ Hôpital de District de Bogodogo, Ouagadougou, Burkina Faso \\ ${ }^{4}$ Hôpital National Blaise Compaoré, Ouagadougou, Burkina Faso \\ ${ }^{5}$ Centre Municipal de Santé Bucco-Dentaire, Ouagadougou, Bukina Faso \\ Email: ouedraogoy@yahoo.fr
}

How to cite this paper: Youssouf, O., Seydou, O., Augustin, S., Médina, F., Désiré, K.W.A., Rasmané, B. and Tarcissus, K. (2017) Surgical and Orthodontic Treatment of Dental Retentions: A Case Report. Open Journal of Stomatology, 7, 463-468. https://doi.org/10.4236/ojst.2017.711041

Received: September 20, 2017

Accepted: November 5, 2017

Published: November 9, 2017

Copyright $\odot 2017$ by authors and Scientific Research Publishing Inc. This work is licensed under the Creative Commons Attribution International License (CC BY 4.0).

http://creativecommons.org/licenses/by/4.0/

\section{Open Access}

\begin{abstract}
This paper reports the case of K.Z, a 15 year-old child received in the Dental Surgery Unit of the Yalgado Ouédraogo Teaching Hospital for consultation for some aesthetic reasons due to dental retentions. On his X-ray, the premolars $25,34,35,44,45$ and the molar 47 were deeply impacted, retained by supernumerary teeth. The treatment consisted in the removal of persistent temporary teeth and supernumerary teeth with poor radicular set, except one premolar. The removal of this premolar located between the roots of tooth 36, was source of major risk; therefore, it was put under clinical supervision. After these extractions, a fixed orthodontic appliance enabled bringing impacted teeth to a functional position. Orthodontic treatment lasted 3 years with a monthly check-up. Ours results are stable after one year of decline.
\end{abstract}

\section{Keywords}

Impacted Teeth, Supernumerary, Mesiodens, Orthodontic

\section{Introduction}

The adult human being normally has 32 teeth. It may happen that some teeth do not appear. They may be retained in their bone base beyond the normal date of appearance. The causes of these dental inclusions are multiple. Hereditary factors or mechanical obstacles are sometimes associated [1] [2]. In the literature review, several studies evaluated the rate of impacted teeth occurrence to vary between $0.3 \%$ and $3.2 \%$ among the population [2] [3] [4]. They are sources of 
either functional or aesthetic consequences.

Mechanical obstacles to dental eruption include supernumerary teeth. The discovery of supernumerary teeth is often made at random during radiological examination which plays a key role in their diagnosis.

Retained teeth can be cared through three options [4] [5]:

- therapeutic abstention if the included tooth is not source of any danger;

- tooth removal if it constitutes a threat to the other teeth;

- orthodontic and surgical treatment.

We report here the case of a 15-year-old boy with supernumerary teeth and impacted premolars and molar, treated by surgery and orthodontics.

\section{Observation}

We had received for consultation the child K.Z. aged 15 years in the Dental Surgery Unit at Yalgado Ouédraogo Teaching Hospital. The reason for consultation was aesthetic; the presence of an additional upper central incisor (Figure 1(b)), spaces between his teeth and persistent of milk tooth in the arch. He had no problem listed general health; he had no significant medical or surgical history. We noticed the presence of a mesiodens in her 12-year-old sister (Figure 2). The questioning brought out the presence of a mesiodens in their mother.

No particular signs were noticed on exobuccal examination. The smile was not nice due to the presence of diastemas and a supernumerary conical tooth between its upper central incisors.

The endobuccal examination (Figures $1(\mathrm{a})-(\mathrm{c})$ ) revealed that oral hygiene was average. There were large upper inter-incisive diastemas with the presence of a mesiodens. The persistence of lacteal teeth $65,74,84$ and 85 was also noticed as well as an exoclusion of the tooth 24 in a vestibular position.

While we expected a diagnosis of dental agenesis responsible for the persistence of milk teeth, we fortuitously discovered supernumerary teeth on X-rays. The examination of the dental panoramic revealed the presence of many additional teeth. We requested a dentascan in order to have more details about their number and their position. On these radiological images (Figure 3(a) and Figure $3(\mathrm{~b})$ ), the premolars $25,34,35,44,45$ and the molar 47 were deeply impacted. These teeth had a complete radicular edification. Their eruption was blocked by odontomas. The second molar, which had grown nearly for 12 years, had made their eruption except for the tooth 47. A supernumerary premolar appeared between the roots of the first lower left molar. At this area, the palpation showed a curvature indicating a vestibular position of the premolar according to the molar.

Therapeutics consisted, on the one hand, in extracting the teeth $(65,74,85)$ and odontomas under local anesthesia. We started on the right side. Extractions on the left side occurred two weeks later. At each session, antibiotic (amoxicillin), analgesic (paracetamol) and mouthwash were prescribed. The operative results were simple. 


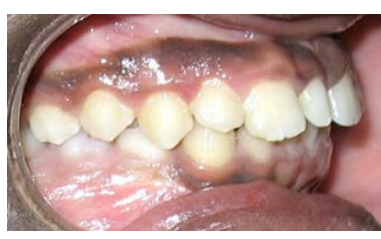

(a)

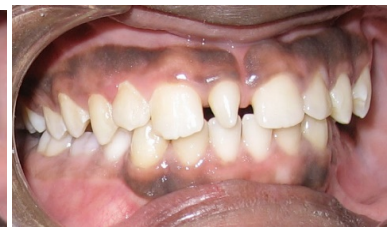

(b)

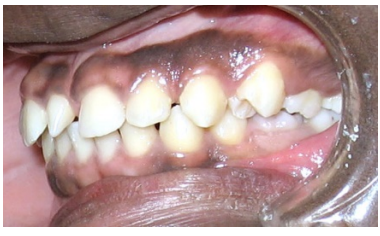

(c)

Figure 1. Endobuccal images before treatment; mesiodens between the central teeth.

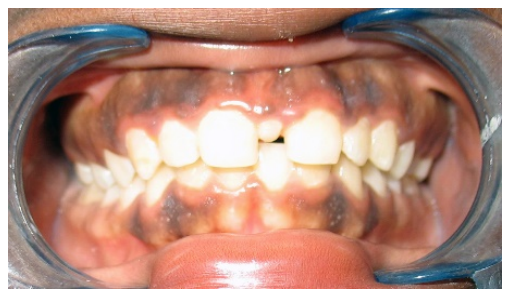

Figure 2. The teeth of his sister, mesiodens between the central teeth.

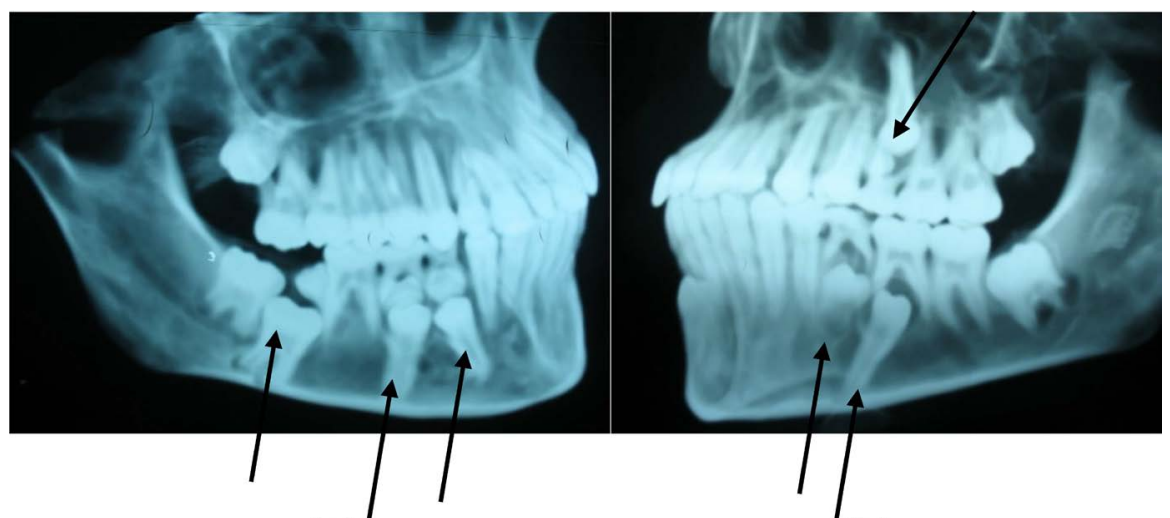

(a)

(b)

Figure 3. Radiographies showing supernumerary and impacted teeth $(25,35,35$ bis, 44 , $45,47)$.

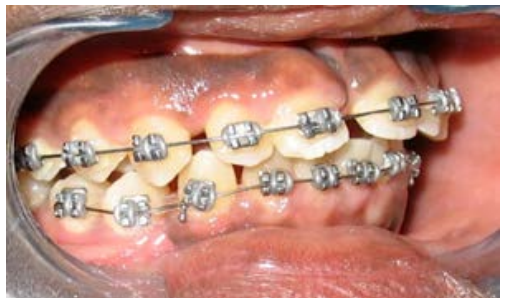

Figure 4. The orthodontic appliance.

On the other hand, the use of a fixed orthodontic appliance Roth 0.22 (Figure 4), enabled the extraction and placing the impacted teeth under a functional occlusion. During the extraction sessions, mucoperiosteal flaps of total thickness allowed the discovery of premolars. A vestibular and lingual or palatal flap is peeled on few millimeters. The crestal bone is then removed to the cuspid point of the impacted tooth. An orthodontic brace is glued to the occlusal surface. The flaps were closed and sutured with absorbable sutures. The chain of the brace extended beyond the level of the gum to serve as anchorage for traction. The 
traction started a month later with elastic ligatured on a steel arch of section $17 / 25$. The patient was reviewed every month for a renewal of the traction elastics. For success, this good cooperation of the patient is essential. After the forced eruption of the different teeth, the bonding was resumed more conventionally on the vestibular faces and a niti leveling arc wire was put in place (Figure 4).

The closing of the spaces was made through a backward set-up. The active treatment lasted three years. No treatment was recommended for the supernumerary premolar located between the roots of the tooth 36 (Figure 5). It showed no sign at both clinical and radiological levels. His closeness to the mental hole and the roots of the tooth 36 did not impose any treatment, but a monitoring twice a year.

A canine-to-canine retainer was placed on the mandible. Our results are stable after one year (Figures 6(a)-(c)). To monitor the supernumerary premolar that remained impacted, the patient is received twice a year for routine check-up.

\section{Discussion}

The odontomas are present in the family of our patient. Heredity may play a role in the pathogenesis of this anomaly, since the supernumerary teeth are more common in children of people with the disease, according to an autosomal recessive or dominant transmission [2].

For the treatment of our patient, the three conventional therapeutic options of the impacted teeth [5] [6] [7] [8] [9] were given. The choice of the teeth to be preserved must be based on the long-term prognosis of the different elements. The natural teeth should be preferred over dental prostheses for reasons of durability and cost of prostheses. Also, maintenance of structures including pros-

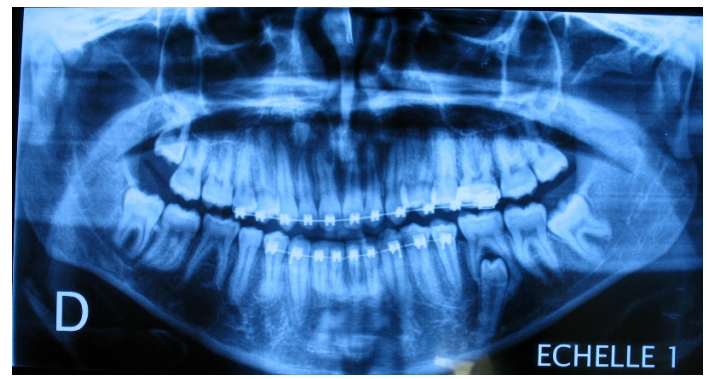

Figure 5. Control of the teeth panoramic; supernumerary premolar persisting between the dental roots of the $36^{\text {th }}$ tooth.

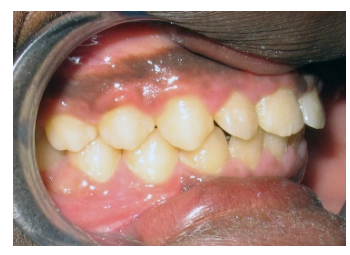

(a)

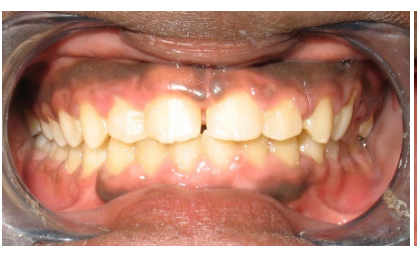

(b)

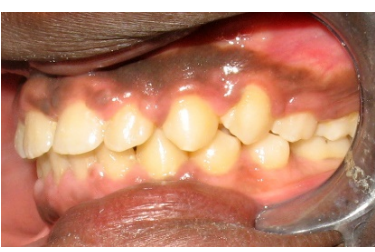

(c)

Figure 6. Images at the end of treatment. 
thetic implant-supported is very demanding and sometimes a source of failure.

Surgical removals focused on multiple odontomas which prevented teeth with a good radicular setting from being on the dental arch. The always conical mesiodens through its central position makes the smile not nice. Its removal followed by the orthodontic closure of the space is recommended [2]. The installation of the orthodontic appliance, which is the often preferred option for impacted teeth, has enabled the premolars and the lower right second molar to be occluded.

Lastly, the non-removal and the monitoring of a second supernumerary left lower premolar because its removal was source of obvious risks. Indeed, the removal of this tooth requires a flap of total thickness and a bone resection. It is located between the roots of the first lower molar, just behind the chin hole where the chin nerve starts. The risk of injuring these surrounding sets is real and requires to be careful. Furthermore, it was impossible to obtain a functional dental occlusion by removing the molar to be replaced by the supernumerary premolar. Yet, with three premolars instead of two, the occlusal movement cannot be perfect and the masticatory coefficient would be reduced in this area. The active treatment did not concern the tooth 36 ; any movement can be source of a radicular resorption through the compression with the underlying tooth.

Otherwise, after the removal of an impacted tooth, it can be subject to selftransplantation [10]. The impacted tooth is removed and then set in a normal position. This option often bears unpredictable consequences. By cutting the pulp, self-transplantation often causes dental necrosis. Failures like root resorption may occur, even in the long term.

Dental removal in the case of impaction can also be replaced with an implant plier. The prosthetic solution is used when the orthodontic option is tedious. One of its advantages is the shorter time for its setting. Nevertheless, it applies only to adult patients at the end of the maxillofacial growth. This option cannot be applied for our patient.

\section{Conclusions}

The treatment of the impacted or supernumerary teeth requires a prognosis on each dental structure. The teeth with the best coronary and radicular sets should be preferred. Therefore, this requires radiological imaging for the analysis and the establishment of a therapeutic plan. In the treatment strategy, long-term advantages for the patient should always be considered. Surgical-orthodontic treatment remains the best option. The removal of the impacted tooth may be expected; either it is set in a favorable position or replaced by an implant-supported dental prosthesis.

To manage complex cases, it is essential to lay emphasis on the main abstentionist dogma of medicine: primum non nocere. In this case, the impacted located between the roots of the tooth 36 is therefore subject to clinical and radiological control, at least once a year. 
The management of the impacted tooth is often long and requires good collaboration between the orthodontist for the traction of the teeth, the periodontist for the surgery and the patient for his understanding of the therapeutic choice and cooperation.

\section{Conflict of Interest}

All the authors declare: We have no conflict of interest.

\section{Informed Consent}

In relation to publication of this case report, consentment was given by the patient's parents.

\section{References}

[1] Marteau, J.M. and Boileau, M.J. (2014) Impacted Teeth Semiotics and Therapeutic Principles. Encyclopédie Médico-Chirurgicale, 23-492-A-10.

[2] Mossaz, J., Sutuer, V.G.A., Katsaros, C. and Bornstein, M.M. (2016) Supernumerary Teeth in the Maxilla and the Mandible-An Interdisciplinary Challenge: Part 1 Epidemiology, Etiology, Classifications and Possible Complications. Swiss Dental Journal SSO, 126, 141-149.

[3] Bourzgui, F., Belhaj, S., Tazi, H., Hamza, M. and Khazana, M.M. (2009) Surgical and Orthodontic Management of Dental Retention. Inter Orthodontic, 7, 257-267. https://doi.org/10.1016/S1761-7227(09)73501-6

[4] Mossaz, J., Sutuer, V.G.A., Katsaros, C. and Bornstein, M.M. (2016) Supernumerary teeth in the Maxilla and Mandible-An Interdisciplinary Challenge: Part 2 Diagnosis and Therapeutic Concepts. Swiss Dental Journal SSO, 126, 249-259.

[5] Ouédraogo, Y., Benyahia, H., Konsem, T., Beugré, J.B., Sonan, K., Ouédraogo, D. and Ouoba, K. (2015) Topography of Impacted Canine: Therapeutic Implications. Revue du COSA-CMF, 22, 18-22.

[6] Sanu, O.O., Adeyemi, T.A. and Isiekwe, M.C. (2012) Incidence of Impacted Mandibular Canine and Associated Pathologies in an Orthodontic Patient Population in Lagos, Nigeria. Nigerian Quaterly Journal of Hospital Medecine, 22, 291-295.

[7] Moffitt, A.H. (2014) Orthodontic and Chirurgical Management of Impacted Teeth. American Journal of Orthodontics and Dentofacial Orthopedics, 145, 843 p.

[8] Mah, M. and Takada, K. (2016) Orthodontic Management of the Inclusion of the Second Mandibular Molar. L'Orthodontie Française, 87, 301-308. https://doi.org/10.1051/orthodfr/2016034

[9] Russell, K.A. and Folwarczna, M.A. (2003) The Mesiodens: Diagnosis and Treatment of a Common Supernumerary Tooth. Journal of the Canadian Dental Association, 69, 362-366.

[10] Gault, P. (2013) The Transplantation of the Impated Canines. L'Orthodontie Française, 84, 221-240. https://doi.org/10.1051/orthodfr/2013058 